\title{
Factors impacting long-term pulmonary autograft durability after the Ross procedure
}

Ravil Sharifulin, MD, Alexander Bogachev-Prokophiev, MD, Sergey Zheleznev, MD, Igor Demin, MD, Alexey Pivkin, MD, Alexander Afanasyev, MD, and Alexander Karaskov, MD

\section{ABSTRACT}

Objective: Although the Ross procedure provides excellent long-term survival and a high quality of life, its use has been limited to relatively few centers. In this study, we evaluated long-term Ross procedure results in adults to assess the predictors of pulmonary autograft durability.

Methods: Between 1998 and 2015, 793 consecutive adult patients underwent the Ross procedure. The total root replacement technique was used in all patients.

Results: The early mortality rate was $2.9 \%$. The mean follow-up duration was $6.5 \pm 3.2$ years, and the 10 -year survival rate was $90.4 \%$. Longitudinal mixedeffects ordinal regression identified a combination of bicuspid aortic valve and aortic insufficiency (odds ratio, $2.19 ; P<.001$ ) as predictors for progression of autograft valve insufficiency at follow-up. The cumulative incidence of autograft reoperations at 10 years was $8.6 \%$. Competing risk regression identified bicuspid aortic valve insufficiency as the independent predictor of autograft reoperation (subdistribution hazard ratio, 2.16; $P=.030$ ). Moreover, patients with bicuspid aortic valve and aortic insufficiency had greater increases in annulus $(P<.001)$, sinus $(P<.001)$, and ascending aorta $(P<.001)$ diameters over time.

Conclusions: For patients undergoing the Ross procedure, a combination of bicuspid aortic valves and aortic insufficiency is the main risk factor for late autograft dilatation and dysfunction. (J Thorac Cardiovasc Surg 2019;157:134-41)

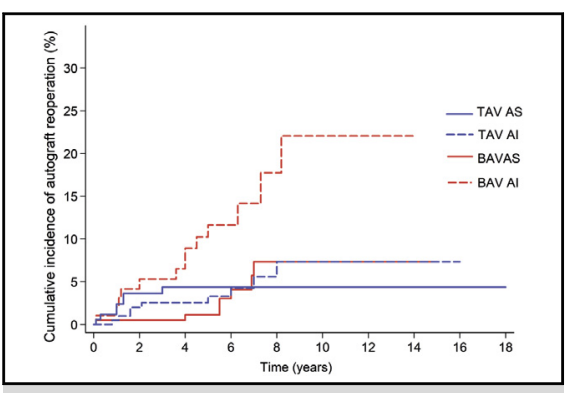

Cumulative incidence of autograft reoperation depends on valve anatomy and hemodynamics.

\section{Central Message}

Combination of bicuspid aortic valve and aortic insufficiency is the risk factor for late autograft dilatation and dysfunction.

\section{Perspective}

The use of the Ross procedure has been limited to relatively few centers. This study showed that patients with bicuspid aortic valves and aortic insufficiency have higher risks of autograft dysfunction and reoperation. These results are useful for selecting patients for the Ross procedure.

See Editorial Commentary page 142.
The Ross procedure is an alternative method of aortic valve disease correction that offers several advantages over conventional aortic valve replacement, including physiological hemodynamics, freedom from lifelong anticoagulation, significantly lower thromboembolism risk, and excellent long-term survival. ${ }^{1,2}$ However, the application of the procedure has been limited to relatively few centers and predominantly to the pediatric population. ${ }^{3,4}$ Regardless,

From the Heart Valve Surgery Department, E. Meshalkin National Medical Research Center, Novosibirsk, Russian Federation.

Read at The American Association for Thoracic Surgery Aortic Symposium 2018, New York, New York, April 26-27, 2018.

Received for publication Oct 14, 2016; revisions received April 27, 2018; accepted for publication May 8, 2018; available ahead of print July 10, 2018.

Address for reprints: Ravil Sharifulin, MD, 15, Rechkunovskaya St, Novosibirsk,

Russian Federation 630055 (E-mail: ravil-sharifulin@rambler.ru).

$0022-5223 / \$ 36.00$

Copyright (c) 2018 by The American Association for Thoracic Surgery

https://doi.org/10.1016/j.jtcvs.2018.05.046 the characteristics of the ideal candidate for the procedure remains unclear. In particular, the use of this procedure in patients with bicuspid aortic valves (BAVs) is controversial. $^{5,6}$ In this study, we evaluated long-term Ross procedure results, in adults, to assess the predictors of pulmonary autograft durability.

\section{METHODS}

\section{Patients}

The study was approved by our institutional review board, and the need for informed patient consent was waived. Between December 1998 and December 2015, 793 consecutive adult patients (18 years old or older)

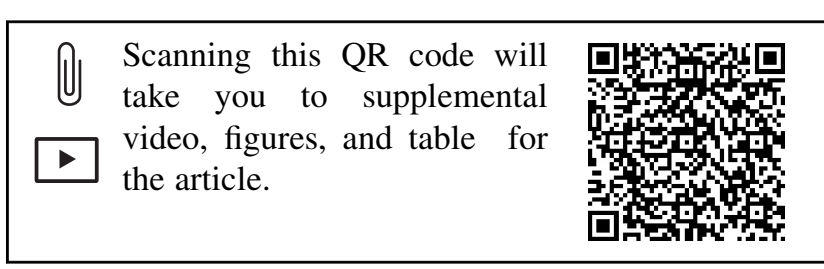




\author{
Abbreviations and Acronyms \\ $\mathrm{BAV}=$ bicuspid aortic valve \\ $\mathrm{CI}=$ confidence interval \\ $\mathrm{OR}=$ odds ratio \\ $\mathrm{RVOT}=$ right ventricular outflow tract \\ $\mathrm{SE} \quad=$ standard error \\ SHR = subdistribution hazard ratio \\ $\mathrm{TAV}=$ tricuspid aortic valve
}

underwent the Ross procedure at our institute. The annual number of the Ross procedures during the study period is shown in Figure E1. Retrospective analysis of the results was performed. The mean patient age was $46.5 \pm 12.4$ years (range, 18-67 years). A primary aortic valve lesion was the main indication for surgery, in accordance with the American College of Cardiology/American Heart Association guidelines for the management of patients with valvular heart disease. ${ }^{7}$ The contraindications for the Ross procedure included pulmonary valve anomalies, connective tissue disorders, other valve pathologies requiring replacement, and multivessel coronary artery diseases. Aortic stenosis was present in 372 patients $(46.9 \%)$, aortic insufficiency in $325(41.0 \%)$, and $96(12.1 \%)$ patients had mixed lesions. The baseline patient characteristics are shown in Table 1.

\section{Surgical Technique}

Cardiopulmonary bypass followed a standard procedure involving aortic and bicaval cannulation, combined with moderate hypothermia $\left(33^{\circ} \mathrm{C}-34^{\circ} \mathrm{C}\right)$. Myocardial protection was achieved using antegrade cardioplegia (Custodiol; Dr Kohler Pharma, Alsbach-Hahnlein, Germany). A total root replacement technique was performed in all patients. The pulmonary autograft was implanted at the level of the aortic annulus, with the proximal anastomosis performed using continuous $5 / 0$ polypropylene (Prolene [Ethicon, Cincinnati, Ohio] or Premilene [B. Braun Melsungen, Melsungen, Germany]) stitches. In patients with tricuspid aortic valves (TAVs), the pulmonary autograft was oriented with its anterior sinus in the noncoronary aortic sinus and the left sinus in the right coronary sinus, fitting the orientation of the native aortic valve commissures. In patients with BAVs, the pulmonary autograft implantation was performed considering the positions of the coronary artery ostia, with symmetrical autograft commissure orientation (commissural orientation near $120^{\circ}$ ). The aortic annulus was dilated in 245 patients (30.9\%). Since 2012, we have routinely applied aortic annulus management. Annulus management was performed in 120 patients $(15.1 \%)$, including the use of proximal suture line reinforcement with pericardial strips in 37 patients $(4.7 \%)$, plication commissural stitches in 56 patients $(7.1 \%)$, and subannular purse-string sutures in 27 patients $(3.4 \%)$. In 20 patients $(2.5 \%)$, external reinforcement of the pulmonary autograft, using a vascular graft, was performed (Video 1). The autograft was inserted into a Dacron vascular prosthesis (B. Braun Melsungen), which was 2 to $4 \mathrm{~mm}$ larger than the autograft annulus. The proximal and distal fixations were performed using continuous 5/0 polypropylene sutures. Then, the wrapped autograft was sutured to the aortic annulus using interrupted U-shaped sutures (PremiCron; B. Braun Melsungen). Holes were made in the prosthesis and the coronary buttons were implanted into the autograft using 6-0 running sutures. Finally, a distal anastomosis, between the autograft and the ascending aorta, was performed. The surgical characteristics at the time of the Ross procedure are provided in Table 2.

\section{Postoperative Management}

Oral anticoagulants were prescribed for 3 months postoperatively to patients with xenografts and polytetrafluoroethylene conduits in the right-side
TABLE 1. Baseline patient characteristics

\begin{tabular}{lc}
\hline \multicolumn{1}{c}{ Characteristic } & Value \\
\hline Sex, $\mathrm{n}(\%)$ & \\
Male & $602(75.9)$ \\
Female & $191(24.1)$ \\
Mean age \pm SD, $\mathrm{y}$ & $46.5 \pm 12.4$ \\
\hline Aortic valve disease etiology, $\mathrm{n}(\%)$ & \\
Bicuspid & $306(38.6)$ \\
Rheumatic & $226(28.5)$ \\
Endocarditis & $147(18.5)$ \\
Degenerative & $74(9.3)$ \\
Prosthetic valve dysfunction & $15(1.9)$ \\
Other etiology & $25(3.2)$ \\
Aortic valve hemodynamic lesions, $\mathrm{n}(\%)$ & \\
Stenosis & $372(46.9)$ \\
Insufficiency & $325(41.0)$ \\
Mixed lesion & $96(12.1)$ \\
\hline Previous cardiac surgery, $\mathrm{n}(\%)$ & \\
Aortic valve replacement & $14(1.8)$ \\
Bentall-DeBono & $1(0.12)$ \\
Aortic valve repair & $7(0.9)$ \\
Aortic balloon valvuloplasty & $2(0.25)$ \\
Subvalvular aortic membrane resection & $2(0.25)$ \\
Coarctation resection & $7(0.9)$ \\
PDA ligation & $5(0.6)$ \\
NYHA functional class, $\mathrm{n}(\%)$ & $16(2.0)$ \\
Class I & $235(29.6)$ \\
Class II & $512(64.6)$ \\
Class III & $30(3.8)$ \\
Class IV & $176(22.2)$ \\
\hline Mean left ventricular ejection fraction \pm SD $(\%)$ & \\
Ascending aorta dilatation $(\geq 45$ mm), $\mathrm{n}(\%)$ & 10.9 \\
\hline & \\
\hline &
\end{tabular}

SD, Standard deviation; PDA, patent ductus arteriosus; NYHA, New York Heart Association.

position, and were replaced with low-dose aspirin in patients with sinus rhythm, as documented by 24-hour Holter monitoring. In cases of using pulmonary allografts, low-dose aspirin was initially administered postoperatively.

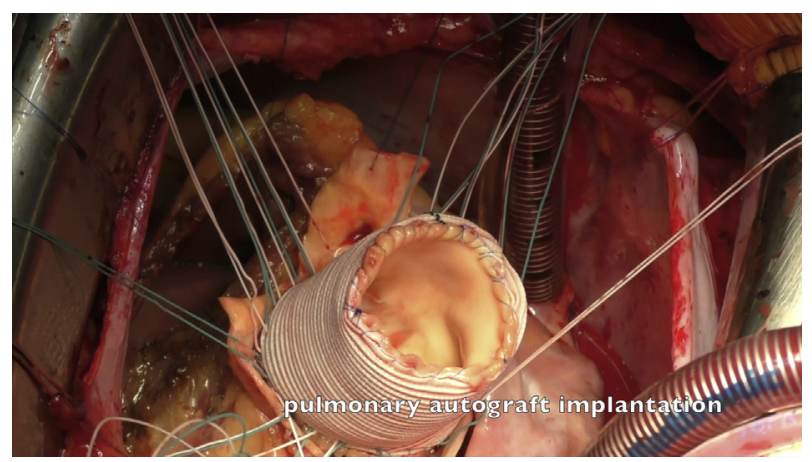

VIDEO 1. External reinforcement of a pulmonary autograft using a vascular graft. Video available at: https://www.jtcvs.org/article/S00225223(18)31468-5/fulltext. 
TABLE 2. Surgical data

\begin{tabular}{lc}
\hline \multicolumn{1}{c}{ Characteristic } & Value \\
\hline Mean cardiopulmonary bypass time $\pm \mathrm{SD}$, min & $154.5 \pm 36.3$ \\
Mean cross-clamp time $\pm \mathrm{SD}, \mathrm{min}$ & $128.6 \pm 24.8$ \\
Aortic annulus dilatation $(\geq 27 \mathrm{~mm}), \mathrm{n}(\%)$ & $245(30.9)$ \\
Aortic annulus management, $\mathrm{n}(\%)$ & $120(15.1)$ \\
\hline Ascending aorta replacement, $\mathrm{n}(\%)$ & $14(1.8)$ \\
Reduction aortoplasty, $\mathrm{n}(\%)$ & $24(3.0)$ \\
Autograft wrapping with Dacron prosthesis, $\mathrm{n}(\%)$ & $20(2.5)$ \\
Concomitant procedures, $\mathrm{n}(\%)$ & \\
Mitral valve repair & $64(8.1)$ \\
Tricuspid valve repair & $41(5.2)$ \\
CABG & $47(5.9)$ \\
Maze IV & $22(2.8)$ \\
VSD closure & $16(2.0)$ \\
RVOT reconstruction, $\mathrm{n}(\%)$ & $185(23.3)$ \\
Pulmonary allograft & $588(74.1)$ \\
Xenografts & $20(2.5)$ \\
\hline PTFE conduit
\end{tabular}

Dacron vascular prosthesis from B. Braun Melsungen (Melsungen, Germany). $S D$, Standard deviation; $C A B G$, coronary artery bypass grafting; $V S D$, ventricular septal defect; RVOT, right ventricular outflow tract; PTFE, polytetrafluoroethylene.

\section{Postoperative Evaluation}

Transesophageal echocardiography (Philips ie33 [Philips Healthcare, Cleveland, Ohio] or Vivid 7 [General Electric Healthcare, Little Chalfont, United Kingdom]) was performed, after weaning each patient off cardiopulmonary bypass, to evaluate the autograft function. Transthoracic echocardiography was also performed before discharge and during the annual follow-up examinations. When annual clinic visits were not possible, echocardiograms, obtained from the patient's local physician, were analyzed at our institute. Echocardiographic evaluations were performed according to the American Society of Echocardiography and the European Association of Echocardiography recommendations. ${ }^{8,9}$ The severity of autograft regurgitation was assessed using color flow Doppler in the parasternal long-axis, short-axis, and apical 5-chamber views and was graded as none/trivial (0), mild (1), moderate (2), or severe (3). Two-dimensional measurements of the autograft and ascending aorta were made in the parasternal long-axis view at 3 levels: the annulus (at the level of the autograft leaflet hinges), the sinuses of Valsalva, and the maximal diameter of the proximal ascending aorta. Left ventricular volumes and ejection fraction were measured using a 2-dimensional-based biplane method of disks summation from the apical 4- and 2-chamber views. The follow-up was closed in May 2017.

Postoperative events were presented according to the Society of Thoracic Surgeons/American Association for Thoracic Surgery/European Association for Cardio-Thoracic Surgery guidelines. Early mortality was defined as death occurring during in-hospital stay or within 30 days after the procedure; late mortality was defined as death occurring after that period. Autograft reoperation was defined as any surgical procedure performed on the autograft.

\section{Statistical Analysis}

Statistical analyses were performed using STATA, version 13.0 (StataCorp, College Station, Tex). Continuous data are presented as mean $\pm \mathrm{SD}$ and categorical data as absolute numbers and relative frequencies. The Kaplan-Meier method was used to evaluate survival. The cumulative incidence of autograft reoperation was estimated using competing risk analysis

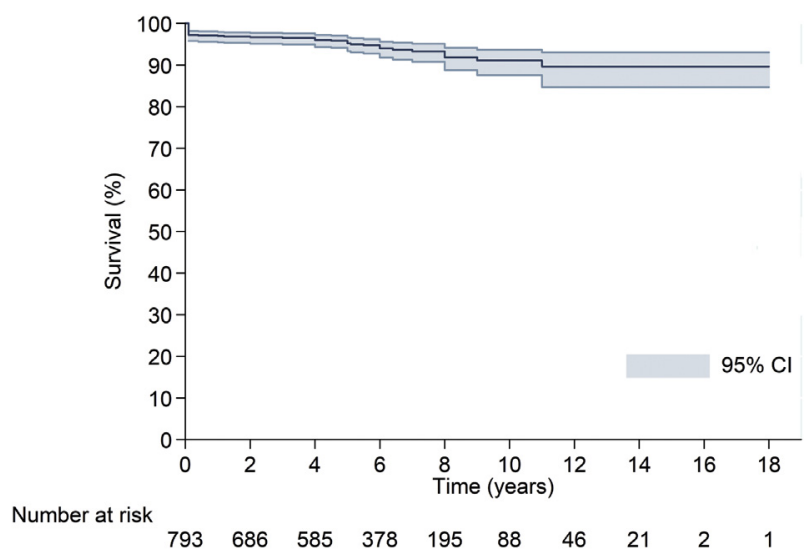

FIGURE 1. Survival. $C I$, Confidence interval.

with death as the competing event and compared between subgroups (patients with BAV stenosis, BAV insufficiency, TAV stenosis, and TAV insufficiency) with the Gray test. Linearized event rates were calculated for valve-related events. The competing risk regression model was used to identify predictors of autograft reoperation, and subdistribution hazard ratios (SHRs) with $95 \%$ confidence intervals (CIs) are reported. Variables, such as age, sex, aortic valve morphology (bicuspid or tricuspid), aortic valve lesion (stenosis or insufficiency), combination of BAV morphology and aortic insufficiency, preoperative active endocarditis, previous surgeries, preoperative aortic annulus, sinus and ascending aorta diameters (continuous variables), annulus reduction, autograft reinforcement, and concomitant ventricular septal defect repair were tested as potential risk factors for autograft reoperation. The assumption of proportional subdistribution hazard was verified using Schoenfeld residuals. The longitudinal mixed effects linear and ordinal models were used to assess changes in functional status and echocardiographic measurements of hemodynamic variables while accounting for the correlation between repeated measurements in each patient. The following variables were included in the linear and ordinal mixed effect models: sex, aortic valve morphology (bicuspid or tricuspid), aortic valve lesion (stenosis or insufficiency), combination of BAV and preoperative aortic insufficiency, preoperative active endocarditis, previous surgeries, preoperative aortic annulus, sinus and ascending aorta diameters (continuous variables), annulus reduction, autograft reinforcement, concomitant ventricular septal defect repair, and postoperative measurement time points were included as fixed effects, and the unique patient identification number as random effects. Two-sided $P$ values of $<.05$ were considered statistically significant.

\section{RESULTS}

The early mortality rate was $2.9 \%$ (23 patients). The causes of these deaths were low cardiac output syndrome (16 patients; $69.6 \%$ ), massive intraoperative bleeding ( 5 patients; $21.7 \%$ ), and deep sternal wound infections in 2 patients $(8.7 \%)$. The mean follow-up period was $6.5 \pm 3.2$ years (range, 6 months to 18 years; 4405 patient-years) and was $95.1 \%$ complete (732 patients); 38 patients were lost to follow-up because contact with these patients was unavailable.

Twenty-two patient deaths occurred during the follow-up period. The late deaths were sudden and unexplained in 12 patients. Three patients died because of progression of heart failure, 1 due to ischemic stroke, and 2 patients died 


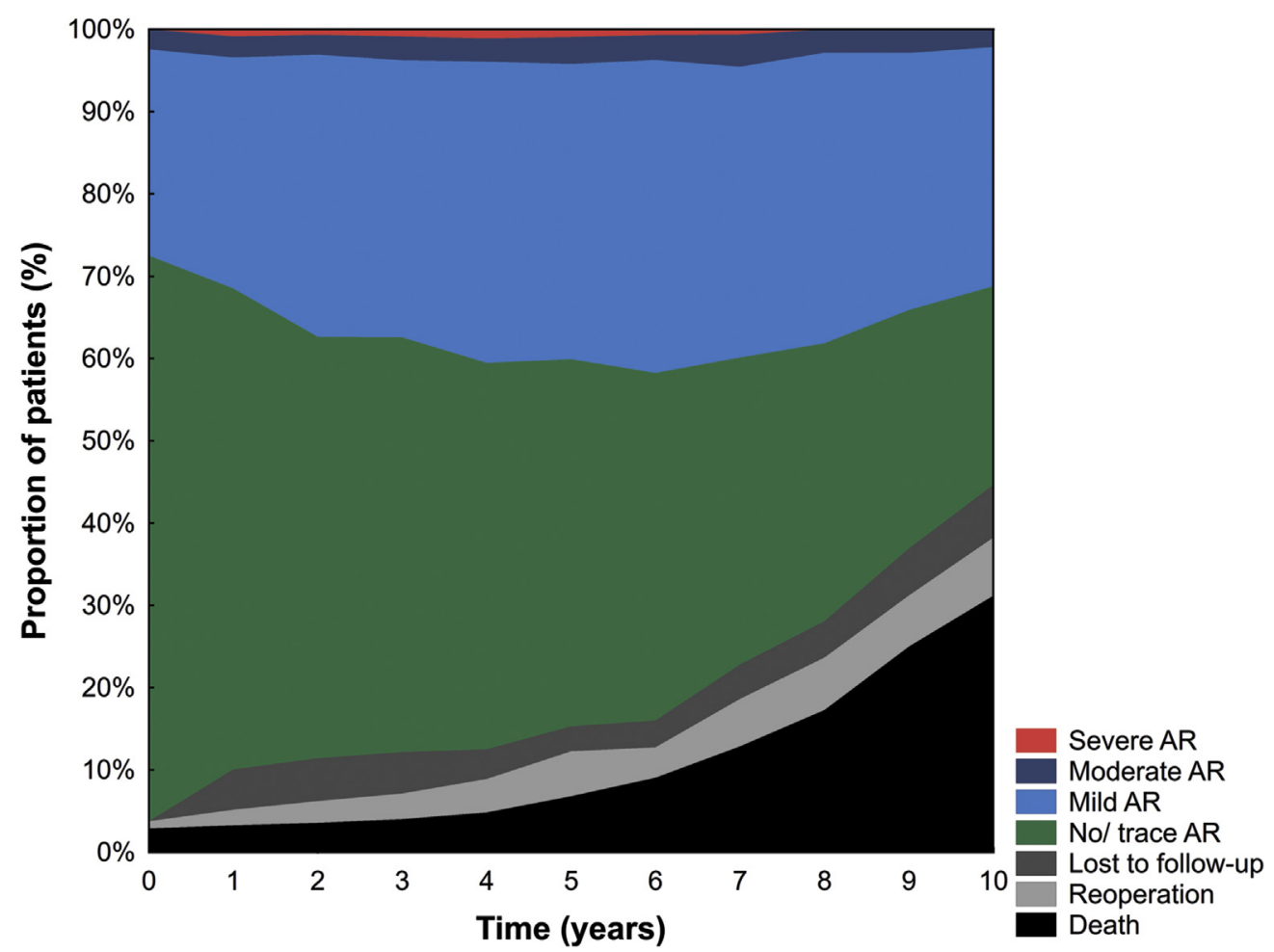

FIGURE 2. Aortic regurgitation $(A R)$ after the Ross procedure, over time.

intraoperatively during reoperations. The other 4 deaths were noncardiac-related. The 5- and 10-year survival rates were $94.6 \%$ (95\% CI, 92.5\%-96.1\%) and 90.4 (95\% CI, $86.4 \%-93.3 \%$ ), respectively (Figure 1).

There were significant improvement of New York Heart Association functional class at 1-year follow-up compared with preoperative functional status $(P<.001$; Figure E2). New York Heart Association class did not change significantly during follow-up (odds ratio [OR], 1.02; 95\% CI, $0.99-1.06 ; P=.073$ ).

Thromboembolic events were registered in 9 patients, with strokes in 3 patients, transient ischemic attacks in 5 , and retinal artery thrombosis in 1 . The linearized rate of thromboembolic events was $0.21 \%$ per patient-year. Major bleeding episodes occurred in 4 patients $(0.09 \%$ per patient-year). Twenty-four patients had autograft infective endocarditis $(0.55 \%$ per patient-year). Eleven patients required autograft reoperation because of severe aortic insufficiency, others were treated conservatively with resolution of the condition. Actuarial curves of thromboembolism, bleeding, and endocarditis are shown in Figure E3.

Twenty-five patients developed moderate aortic insufficiency and 37 developed severe aortic insufficiency postoperatively. Progression of aortic insufficiency, over time, is shown in Figure 2, and the relevant data are presented in Table E1. Longitudinal mixed-effects ordinal regression identified BAV insufficiency (OR, 2.19; 95\% CI, 1.59-
3.02; $P<.001)$ as a predictor for progression of autograft valve insufficiency at follow-up (Table 3).

A gradual increase in autograft annulus $(0.26 \pm 0.01$ $\mathrm{mm} / \mathrm{y} ; P<.001)$, sinus $(0.36 \pm 0.01 \mathrm{~mm} / \mathrm{y} ; P<.001)$, and ascending aorta diameters $(0.32 \pm 0.02 \mathrm{~mm} / \mathrm{y}$; $P<.001$ ), over time, was found. Autograft dilatation (maximum diameter $\geq 45 \mathrm{~mm}$ ) was found in 74 patients. Three patients had autograft or aortic diameters $>50 \mathrm{~mm}$ and required reoperations. The proportion of patients with autograft dilatation $(\geq 45 \mathrm{~mm})$ increased during follow-up (OR, 4.1; 95\% CI, 3.37-4.98; $P<.001$; Figure E4).

Longitudinal mixed effects linear modeling revealed that preoperative annulus diameter (regression coefficient \pm standard error $[\mathrm{SE}], 0.17 \pm 0.2 ; P<.001)$ and $\mathrm{BAV}$ insufficiency (regression coefficient $\pm \mathrm{SE}, 1.09 \pm 0.15$; $P<.001)$ were predictors of annulus diameter progression. At discharge, the aortic annulus diameter was slightly higher in the patients with BAV insufficiency compared with those with TAV stenosis $(25.0 \pm 2.2$ vs $24.3 \pm 1.2 \mathrm{~mm}$; $P=.057)$ and did not differ compared with those with BAV stenosis $(24.4 \pm 2.0 \mathrm{~mm} ; P=.160)$ or TAV insufficiency $(24.6 \pm 1.3 \mathrm{~mm} ; P=.464)$. The patients with BAV insufficiency revealed greater increases in annulus diameters during follow-up than those with TAV stenosis $(0.37 \pm 0.02$ vs $0.21 \pm 0.02 \mathrm{~mm} / \mathrm{y} ; P<.001)$, TAV insufficiency $(0.37 \pm 0.02$ vs $0.26 \pm 0.02 \mathrm{~mm} / \mathrm{y} ; P<.001)$, or BAV stenosis $(0.37 \pm 0.02$ vs $0.27 \pm 0.03 \mathrm{~mm} / \mathrm{y} ; P<.001)$. 
TABLE 3. Change over time in aortic regurgitation grade (longitudinal mixed-effects ordinal model)

\begin{tabular}{lcc}
\hline \multicolumn{1}{c}{ Risk factor } & OR $(\mathbf{9 5} \%$ CI) & $\boldsymbol{P}$ value \\
\hline Male sex & $0.69(0.44-1.10)$ & .124 \\
Valve lesion (AI) & $1.08(0.90-1.31)$ & .406 \\
\hline Bicuspid aortic valve & $1.18(0.97-1.44)$ & .101 \\
Bicuspid aortic valve with AI & $2.19(1.59-3.02)$ & $<.001$ \\
\hline Endocarditis & $0.55(0.27-1.11)$ & .116 \\
Aortic annulus diameter, mm & $1.05(0.96-1.15)$ & .288 \\
\hline Aortic sinus diameter, mm & $0.99(0.96-1.02)$ & .693 \\
Ascending aorta diameter, mm & $1.02(0.99-1.04)$ & .519 \\
\hline Annulus reduction & $1.66(0.75-3.71)$ & .214 \\
\hline Autograft reinforcement & $1.74(0.82-3.66)$ & .147 \\
\hline Previous operation & $0.71(0.39-1.31)$ & .277 \\
Concomitant VSD repair & $0.65(0.35-1.19)$ & .165 \\
\hline Time after surgery, y & $1.19(1.16-1.22)$ & $<.001$ \\
\hline$O R$ O
\end{tabular}

$O R$, Odds ratio; $C I$, confidence interval; $A I$, aortic insufficiency; $V S D$, ventricular septal defect.

Preoperative sinus diameter (regression coefficient $\pm \mathrm{SE}$, $0.11 \pm 0.04 ; P=.034$ ) and BAV insufficiency (regression coefficient $\pm \mathrm{SE}, 1.29 \pm 0.33 ; P<.001)$ were predictors of sinus diameter increases during follow-up, using the longitudinal mixed-effects linear modeling. At discharge, there were no between group differences in sinus diameters, whereas increases were greater in the BAV insufficiency patients: BAV insufficiency versus TAV stenosis $(0.42 \pm 0.04$ vs $0.26 \pm 0.06 \mathrm{~mm} / \mathrm{y} ; P=.001)$, BAV insufficiency versus TAV insufficiency $(0.42 \pm 0.04$ vs $0.33 \pm 0.03 \mathrm{~mm} / \mathrm{y}$; $P<.001)$, BAV insufficiency versus BAV stenosis $(0.42 \pm 0.04$ vs $0.30 \pm 0.03 \mathrm{~mm} / \mathrm{y} ; P<.001)$.

The predictors of ascending aorta dilatation at follow-up were preoperative ascending aorta diameter (regression coefficient $\pm \mathrm{SE}, 0.09 \pm 0.02 ; P=.012)$ and BAV insufficiency (regression coefficient $\pm \mathrm{SE}, 1.03 \pm 0.29 ; P<.001$ ). During the early postoperative period, the patients with BAV insufficiency had significantly higher ascending aorta diameter compared with patients with TAV stenosis $(35.3 \pm 2.2$ vs $34.1 \pm 1.2 \mathrm{~mm} ; P=.002)$, whereas ascending aorta diameters were similar in BAV stenosis $(35.0 \pm 1.9 \mathrm{~mm} ; P=.494)$ and TAV insufficiency patients $(34.7 \pm 1.6 \mathrm{~mm} ; P=.093)$. The patients with BAV insufficiency revealed a greater increase in ascending aorta diameters during follow-up, compared with those with TAV stenosis $(0.37 \pm 0.06$ vs $0.24 \pm 0.05 \mathrm{~mm} / \mathrm{y} ; P<.001)$, TAV insufficiency $(0.37 \pm 0.06$ vs $0.30 \pm 0.02 \mathrm{~mm} / \mathrm{y}$; $P=.008)$, or BAV stenosis $(0.37 \pm 0.06$ vs $0.28 \pm 0.03 \mathrm{~mm} / \mathrm{y} ; P<.001)$.

During the follow-up period, 62 patients underwent reoperations because of autograft or right ventricular outflow tract (RVOT) graft failure. The cumulative incidence of all reoperations at 10 years was $14.5 \%$ (95\% CI, $10.2 \%$ -
$19.4 \%$ ). Forty patients had autograft dysfunction and underwent reoperations. The main indication for reoperation was severe autograft valve insufficiency (37 patients; $92.5 \%)$. Two patients $(5.0 \%)$ had subvalvular false aneurysm (proximal anastomosis line) and 1 patient $(2.5 \%)$ had ascending aorta aneurysm without hemodynamic autograft disorders. The 5- and 10-year cumulative incidence of autograft reoperations were $4.0 \%(95 \% \mathrm{CI}, 2.7 \%-5.6 \%)$ and $8.6 \%(95 \% \mathrm{CI}, 5.9 \%-12.0 \%)$, respectively. The main reason for autograft valve insufficiency was autograft dilatation. Infective endocarditis alone or in combination with autograft dilatation, was identified in 11 patients $(27.5 \%)$. In 4 patients, autograft valve repair was performed using perforation closure with a xenopericardial patch (2 patients), annuloplasty (1 patient), or the David procedure (1 patient). Other patients underwent mechanical prosthesis implantations. Thirty patients underwent RVOT reinterventions. The cumulative incidence of RVOT reoperations at 10 years was $8.6 \%$ (95\% CI, 5.1\%-13.1\%).

Competing risk regression analyses identified aortic BAV insufficiency $(P=.001)$ and preoperative aortic annulus diameter $(P=.004)$ as independent predictors of autograft reoperation, whereas multivariable analyses confirmed BAV insufficiency as the only risk factor for autograft reoperation $(P=.015$; Table 4$)$. There were 13 autograft reoperations in the BAV insufficiency subgroup, 9 in the TAV insufficiency subgroup, and 7 reoperations in the BAV with TAV stenosis subgroups. The cumulative incidence of autograft reoperation in patients with BAV insufficiency at 10 years was $22.1 \%(95 \% \mathrm{CI}, 10.8 \%-35.9 \%)$. The $10-$ year cumulative incidence of autograft reoperation was significantly lower in patients with TAV stenosis $(4.3 \%$ [95\% CI, 1.9\%-8.4\%]; SHR, 3.0 [95\% CI, $1.19 \%-$ $7.59 \%$ ]; $P=.020)$, TAV insufficiency $(7.2 \%[95 \% \mathrm{CI}$, $3.2 \%-13.5 \%$ ]; SHR, 2.97 [95\% CI, 1.28\%-6.90\%]; $P=.011)$, or BAV stenosis $(7.2 \%[95 \% \mathrm{CI}, 2.9 \%-$ $14.0 \%$ ]; SHR, 3.52 [95\% CI, 1.41\%-8.74\%]; $P=.007$; Figure 3).

\section{DISCUSSION}

Aortic valve replacement with pulmonary autograft offers patients excellent hemodynamics, freedom from lifelong anticoagulation, and minimal risk of thromboembolism. However, there is a worldwide tendency toward a decreasing number of Ross procedures, ${ }^{3}$ which is explained by the periprocedural mortality and morbidity rates that exceed those for standard aortic valve replacements and the higher rates of reoperation because of autograft dysfunction. ${ }^{4}$ In accordance with the current guidelines of the American College of Cardiology/American Heart Association, ${ }^{7}$ the Ross procedure should only be considered in young patients when anticoagulation is contraindicated or undesirable. However, recent studies have shown that post-Ross procedure mortality rates, at specialized centers, are similar to those for 
TABLE 4. Risk factors for autograft reoperation (competing risk regression model)

\begin{tabular}{|c|c|c|c|c|}
\hline \multirow[b]{2}{*}{ Risk factor } & \multicolumn{2}{|c|}{ Univariable regression } & \multicolumn{2}{|c|}{ Multivariable regression } \\
\hline & $\overline{\text { SHR }(95 \% \text { CI })}$ & $P$ value & $\overline{\text { SHR }(95 \% \text { CI })}$ & $P$ value \\
\hline Male sex & $1.65(0.73-3.71)$ & .230 & $2.66(0.59-11.9)$ & .201 \\
\hline Age, y & $0.99(0.96-1.01)$ & .202 & $0.98(0.93-1.03)$ & .376 \\
\hline Valve lesion (AI) & $1.78(0.95-3.35)$ & .073 & $0.78(0.30-1.99)$ & .602 \\
\hline Bicuspid aortic valve & $1.54(0.82-2.90)$ & .179 & $0.75(0.28-2.04)$ & .574 \\
\hline Bicuspid aortic valve with AI & $3.14(1.63-6.10)$ & .001 & $2.16(1.10-6.36)$ & .030 \\
\hline Endocarditis & $1.48(0.66-3.33)$ & .342 & $1.38(0.60-3.17)$ & .444 \\
\hline Aortic annulus diameter, $\mathrm{mm}$ & $1.17(1.04-1.31)$ & .009 & $1.11(0.97-1.26)$ & .133 \\
\hline Aortic sinus diameter, $\mathrm{mm}$ & $1.04(0.98-1.12)$ & .193 & $0.94(0.85-1.03)$ & .190 \\
\hline Ascending aorta diameter, $\mathrm{mm}$ & $0.99(0.95-1.04)$ & .881 & $0.99(0.96-1.04)$ & .893 \\
\hline Annulus reduction & $0.75(0.18-3.11)$ & .689 & $0.88(0.22-3.49)$ & .852 \\
\hline Autograft reinforcement & $2.24(0.79-6.37)$ & .129 & $1.98(0.82-4.78)$ & .127 \\
\hline Previous operation & $1.64(0.41-6.55)$ & .486 & $1.87(0.45-7.82)$ & .391 \\
\hline Concomitant VSD repair & $1.83(0.26-13.1)$ & .544 & $2.06(0.29-14.7)$ & .471 \\
\hline
\end{tabular}

SHR, Subdistribution hazard ratio; $C I$, confidence interval; $A I$, aortic insufficiency; $V S D$, ventricular septal defect.

conventional aortic valve replacements. ${ }^{10,11}$ Moreover, excellent long-term survival rates have been obtained after the Ross procedure, comparable with those for the ageand sex-matched general populations and exceeding those for mechanical prosthesis implantations. ${ }^{8,12}$ Valve-sparing reoperations, after the Ross procedure, have been also shown to be safe options, with 8-year autograft valve preservation rates of $85 \%$ to $90 \%{ }^{13}$ Considering the results of such recent studies, we believe that the Ross procedure will remain on the surgical menu.

A number of risk factors for autograft failure have been presented in the literature, including preoperative aortic insufficiency, ${ }^{10,12,14}$ aortic annulus dilatation, ${ }^{12,14}$ use of the total root replacement technique, ${ }^{15}$ male sex, ${ }^{14,16}$ patient age, ${ }^{17}$ and postoperative arterial hypertension. ${ }^{17}$ $\mathrm{BAV}$ morphology is the most controversial risk factor for

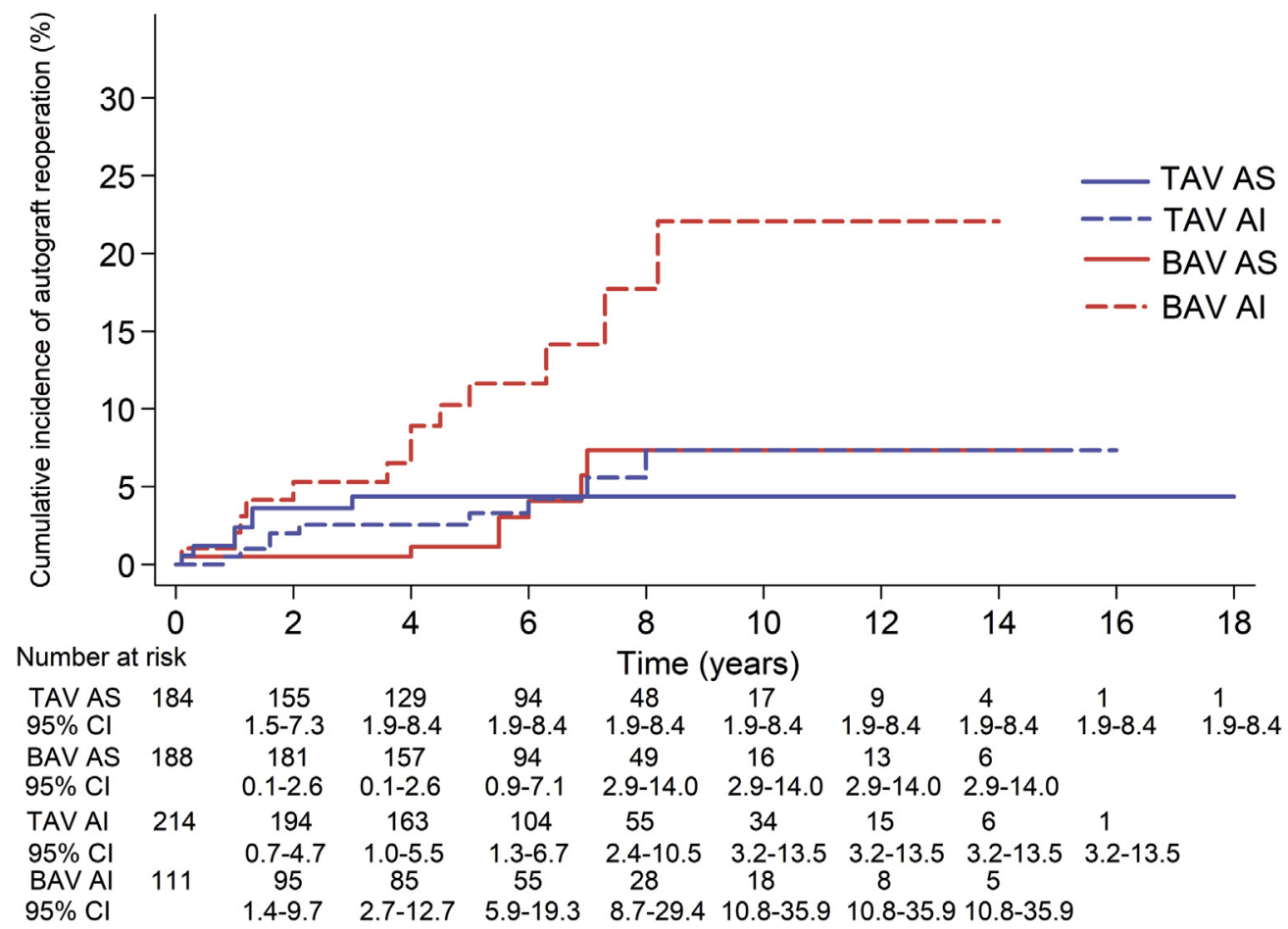

FIGURE 3. Cumulative incidence curves depicting freedom from autograft reoperation, according to aortic valve anatomy and hemodynamic lesions. $T A V$, Tricuspid aortic valve; $A S$, aortic stenosis; $A I$, aortic insufficiency; $B A V$, bicuspid aortic valve; $C I$, confidence interval. 
autograft dysfunction. ${ }^{5,6}$ The recent Society of Thoracic Surgeons aortic valve and ascending aorta guidelines indicate that the Ross procedure is not recommended for patients with BAVs. ${ }^{18}$ However, the level of evidence for this recommendation is low. Because BAV morphology is the leading cause of aortic valve disease in young patients, ${ }^{19}$ the question arises as to who represents the ideal candidate for the Ross procedure?

$\mathrm{BAV}$ is frequently associated with histologic aortic wall abnormalities and aortic dilatation. ${ }^{6,20}$ In some studies, histologic abnormalities of the pulmonary artery in patients with $\mathrm{BAV}^{5}$ and an association between BAV anatomy and pulmonary autograft dysfunction after the Ross procedure have been described. However, only a few studies have shown an impact of BAV morphology on autograft durability. ${ }^{21}$ In contrast, a vast number of studies have indicated that BAV is not a predictor of autograft dysfunction. ${ }^{17,22}$ In the German Ross registry (906 patients with BAV, 371 with TAV), postoperative neoaortic regurgitation rates did not differ between patients with BAV or TAV morphologies; however, a higher degree of aortic root dilatation was observed in the BAV group during follow-up. ${ }^{22}$

BAV morphology represents a phenotypically heterogeneous group of aortic valve malformations. ${ }^{23}$ There are 2 principal types of BAVs, which show different morphological aortic root changes and long-term prognoses: BAV stenosis and insufficiency. ${ }^{23,24}$ Patients with BAV insufficiency are characterized by whole-root dilatation, and evidence suggests that aortopathy in these patients is predominantly genetically determined. In contrast, most patients with BAV stenosis have asymmetric dilatation of the tubular part of the aorta, and hemodynamic disturbance is the main pathogenetic factor leading to aortopathy. ${ }^{23,24}$ Furthermore, histologic lesions in the proximal aortic wall are significantly more severe in patients with BAV insufficiency than in those with BAV stenosis. ${ }^{25,26}$ Patients with BAV insufficiency have also been shown to have a higher risk of aortic events over the long term. ${ }^{24,27}$

Our study revealed that patients with BAVs and preoperative aortic insufficiency had a higher risk of autograft dysfunction and reoperation. Moreover, we found a significantly higher degree of autograft and ascending aorta dilatation at follow-up in patients with BAV insufficiency, compared with those with TAV insufficiency, and TAV and BAV stenosis.

The type of cusp fusion also affects the prevalence and severity of aortopathy. ${ }^{28,29}$ In most studies, left-right fusion is associated with more severe histologic changes in the ascending aorta wall and larger aortic root diameters. ${ }^{29-31}$ Girdauskas et al reported a strong correlation between the structural and hemodynamic parameters of the aortic root (angle between the left ventricle outflow axis and the aortic root and systolic transvalvular flow jet) and histologic changes in the proximal aorta, in patients with BAV stenosis. ${ }^{32}$ Furthermore, the hemodynamic features were shown to differ significantly among patients with the same cusp fusion pattern. ${ }^{32}$ Thus, a Ross procedure outcome assessment, in light of different BAV phenotypes, would be useful.

When the root replacement technique of the Ross procedure is used, reinforcement methods have been shown to decrease the rate of autograft failure. In the GermanDutch Ross registry, the rates of 10-year freedom from autograft reoperation with and without reinforcement procedures were $95.9 \%$ and $87.3 \%$, respectively. ${ }^{15}$ Moreover, implantation of short autografts, cut just above the commissure tips, also reduces the risk of late autograft dilatation and dysfunction. In the study by Yacoub and colleagues, the 10-year freedom from autograft reoperation using short autograft implantation, without additional proximal and distal anastomosis support, was $99 \%{ }^{33}$ Currently, another approach to prevent late autograft dilatation was proposed, comprising autograft insertion into a Dacron or polytetrafluoroethylene graft. ${ }^{34} \mathrm{We}$ used this technique in 20 patients. Although this technique prevents autograft dilatation, it also restricts graft mobility (one of the important advantages of the Ross procedure). Moreover, the long-term results of this technique are unknown, and some experimental studies have reported that the synthetic material induces inflammatory changes and fibrosis in the autograft wall, leading to a loss of elastic properties. ${ }^{35}$ In our study, annulus management and autograft reinforcement with vascular grafts did not affect aortic insufficiency prevention. However, we only started using these techniques routinely within the past 5 years, and the mean follow-up period for these patients is short.

Thus, we consider that patients with BAVs, aortic insufficiency, and dilated annulus have higher risks of autograft dysfunction. However, whether autograft reinforcement procedures prevent late autograft dysfunction in these patients remains controversial.

\section{Study Limitations}

The present study is limited by its retrospective design. Moreover, we did not investigate autograft durability in patients with different BAV morphologies. The mean followup duration of the study was also relatively short; therefore, longer-term follow-up results are needed.

\section{CONCLUSIONS}

For patients undergoing the Ross procedure, a combination of BAVs and aortic insufficiency is the main risk factor for late autograft dilatation and dysfunction. External reinforcement techniques should be considered as an approach of autograft failure prevention. 


\section{Conflict of Interest Statement}

Authors have nothing to disclose with regard to commercial support.

\section{References}

1. Andreas M, Wiedemann D, Seebacher G, Rath C, Aref T, Rosenhek R, et al. The Ross procedure offers excellent survival compared with mechanical aortic valve replacement in real-word setting. Eur J Cardiothorac Surg. 2014;46:409-13.

2. Ouzounian M, Mazine A, David TE. The Ross procedure is the best operation to treat aortic stenosis in young and middle-aged adults. J Thorac Cardiovasc Surg. 2017; $154: 778-82$.

3. Reece TB, Welke KF, O'Brien S, Grau-Sepulveda MV, Grover FL, Gammie JS. Rethinking the Ross procedure in adults. Ann Thorac Surg. 2014;97:175-81.

4. Klieverik LM, Takkenberg JJ, Bekkers JA, Roos-Hesselink JW, Witsenburg M, Bogers AJ. The Ross procedure: a Trojan horse? Eur Heart J. 2007;28:1993-2000.

5. de Sa M, Moshkovitz Y, Butany J, David TE. Histologic abnormalities of the ascending aorta and pulmonary trunk in patients with bicuspid aortic valve disease: clinical relevance to the Ross procedure. J Thorac Cardiovasc Surg. 1999;118:588-94.

6. Luciani GB, Barozzi L, Tomezzoli A, Casali G, Mazzucco A. Bicuspid aortic valve disease and pulmonary autograft root dilatation after the Ross procedure: a clinicopathologic study. J Thorac Cardiovasc Surg. 2001;122:74-9.

7. Nishimura RA, Otto CM, Bonow RO, Carabello BA, Erwin JP III, Guyton RA, et al. 2014 AHA/ACC guideline for the management of patients with valvular heart disease: a report of the American College of Cardiology/American Heart Association task force on practice guidelines. J Thorac Cardiovasc Surg. 2014; 148:e1-132.

8. Lancellotti P, Tribouilloy C, Hagendorff A, Moura L, Popescu BA, Agricola E, et al. European Association of Echocardiography recommendations for the assessment of valvular regurgitation. Part 1: aortic and pulmonary regurgitation (native valve disease). Eur J Echocardiogr. 2010;11:223-44.

9. Lang RM, Badano LP, Mor-Avi V, Afilalo J, Armstrong A, Ernande L, et al. Recommendations for cardiac chamber quantification by echocardiography in adults: an update from the American Society of Echocardiography and the European Association of Cardiovascular Imaging. J Am Soc Echocardiogr. 2015;28:1-39.

10. Weimar T, Charitos EI, Liebrich M, Roser D, Tzanavaros I, Doll N, et al. Quo vadis pulmonary autograft-the Ross procedure in its second decade: a singlecenter experience in 645 patients. Ann Thorac Surg. 2014;97:167-74.

11. Skillington PD, Mokhles MM, Takkenberg JJ, Larobina M, O'Keefe M, Wynne R, et al. The Ross procedure using autologous support of the pulmonary autograft: techniques and late results. J Thorac Cardiovasc Surg. 2015;149:46-52.

12. da Costa FD, Takkenberg JJ, Fornazari D, Balbi Filho EM, Colatusso C, Mokhles MM, et al. Long-term results of the Ross operation: an 18-year single institutional experience. Eur J Cardiothorac Surg. 2014;46:415-22.

13. Mookhoek A, de Kerchove L, El Khoury G, Weimar T, Luciani GB, Mazzucco A, et al. European multicenter experience with valve-sparing reoperations after the Ross procedure. J Thorac Cardiovasc Surg. 2015;150:1132-7.

14. David TE, David C, Woo A, Manlhiot C. The Ross procedure: outcomes at 20 years. J Thorac Cardiovasc Surg. 2014;147:85-93.

15. Charitos EI, Takkenberg JJ, Hanke T, Gorski A, Botha C, Franke U, et al. Reoperations on the pulmonary autograft and pulmonary homograft after the Ross procedure: an update on the German Dutch Ross registry. J Thorac Cardiovasc Surg. 2012; 144:813-21

16. Elkins RC, Thompson DM, Lane MM, Elkins CC, Peyton MD. Ross operation: 16-year experience. J Thorac Cardiovasc Surg. 2008;136:623-30.

17. Takkenberg JJ, Klieverik LM, Schoof PH, Suylen RJ, van Herwerden LA, Zondervan PE, et al. The Ross procedure: a systematic review and meta-analysis. Circulation. 2009;119:222-8.

18. Svensson LG, Adams DH, Bonow RO, Kouchoukos NT, Miller DC, O’Gara PT, et al. Aortic valve and ascending aorta guidelines for management and quality measures. Ann Thorac Surg. 2013;95:S1-66.

19. Joint Task Force on the Management of Valvular Heart Disease of the European Society of Cardiology (ESC), European Association for Cardio-Thoracic
Surgery (EACTS), Vahanian A, Alfieri O, Andreotti F, Antunes MJ, et al. Guidelines on the management of valvular heart disease (version 2012). Eur Heart J. 2012;33:2451-96.

20. Hardikar AA, Marwick TH. Surgical thresholds for bicuspid aortic valve associated aortopathy. JACC Cardiovasc Imaging. 2013;6:1311-20.

21. Settepani F, Kaya A, Morshuis WJ, Schepens MA, Heijmen RH, Dossche KM. The Ross operation: an evaluation of a single institution's experience. Ann Thorac Surg. 2005;79:499-504.

22. Hanke T, Charitos EI, Stierle U, Robinson DR, Hemmer W, Moritz A, et al. The Ross operation - a feasible and safe option in the setting of a bicuspid aortic valve? Eur J Cardiothorac Surg. 2010;38:333-9.

23. Cotrufo M, Della Corte A. The association of bicuspid aortic valve disease with asymmetric dilatation of the tubular ascending aorta: identification of a definite syndrome. J Cardiovasc Med (Hagerstown). 2009;10:291-7.

24. Girdauskas E, Disha K, Raisin HH, Secknus MA, Borger MA, Kuntze T. Risk of late aortic events after an isolated aortic valve replacement for bicuspid aortic valve stenosis with concomitant ascending aortic dilation. Eur J Cardiothorac Surg. 2012;42:832-7.

25. Roberts WC, Vowels TJ, Ko JM, Filardo G, Hebeler RF Jr, Henry AC, et al. Comparison of the structure of the aortic valve and ascending aorta in adults having aortic valve replacement for aortic stenosis versus for pure aortic regurgitation and resection of the ascending aorta for aneurysm. Circulation. 2011;123: 896-903.

26. Girdauskas E, Rouman M, Borger MA, Kuntze T. Comparison of aortic media changes in patients with bicuspid aortic valve stenosis versus bicuspid valve insufficiency and proximal aortic aneurysm. Interact Cardiovasc Thorac Surg. 2013;17:931-6.

27. Girdauskas E, Disha K, Rouman M, Espinoza A, Borger MA, Kuntze T. Aortic events after isolated aortic valve replacement for bicuspid aortic valve roo phenotype: echocardiographic follow-up study. Eur J Cardiothorac Surg. 2015;48:e71-6.

28. Bissell MM, Hess AT, Biasiolli L, Glaze SJ, Loudon M, Pitcher A, et al. Aortic dilation in bicuspid aortic valve disease: flow pattern is a major contributor and differs with valve fusion type. Circ Cardiovasc Imaging. 2013;6:499-507.

29. Schaefer BM, Lewin MB, Stout KK, Gill E, Prueitt A, Byers PH, et al. The bicuspid aortic valve: an integrated phenotypic classification of leaflet morphology and aortic root shape. Heart. 2008;94:1634-8.

30. Della Corte A, Bancone C, Conti CA, Votta E, Redaelli A, Del Viscovo L, et al. Restricted cusp motion in right-left type of bicuspid aortic valves: a new risk marker for aortopathy. J Thorac Cardiovasc Surg. 2012;144 360-9.

31. Della Corte A, Bancone C, Dialetto G, Covino FE, Manduca S, D'Oria V, et al Towards an individualized approach to bicuspid aortopathy: different valve types have unique determinants of aortic dilatation. Eur J Cardiothorac Surg. 2014;45: e118-24.

32. Girdauskas E, Rouman M, Disha K, Scholle T, Fey B, Theis B, et al. Correlation between systolic transvalvular flow and proximal aortic wall changes in bicuspid aortic valve stenosis. Eur J Cardiothorac Surg. 2014;46:234-9.

33. El-Hamamsy I, Eryigit Z, Stevens LM, Sarang Z, George R, Clark L, et al. Longterm outcomes after autograft versus homograft aortic root replacement in adults with aortic valve disease: a randomised controlled trial. Lancet. 2010;376: 524-31.

34. Gebauer R, Cerny S. A modification of the Ross procedure to prevent pulmonary autograft dilatation. Eur J Cardiothorac Surg. 2009;36:195-7.

35. Nappi F, Spadaccio C, Castaldo C, Di Meqlio F, Nurzynska D, Montagnani S et al. Reinforcement of the pulmonary artery autograft with a polyglactin and polydioxanone mesh in the Ross operation: experimental study in growing lamb. $J$ Heart Valve Dis. 2014;23:145-8.

Key Words: aortic valve, pulmonary autograft, Ross procedure 


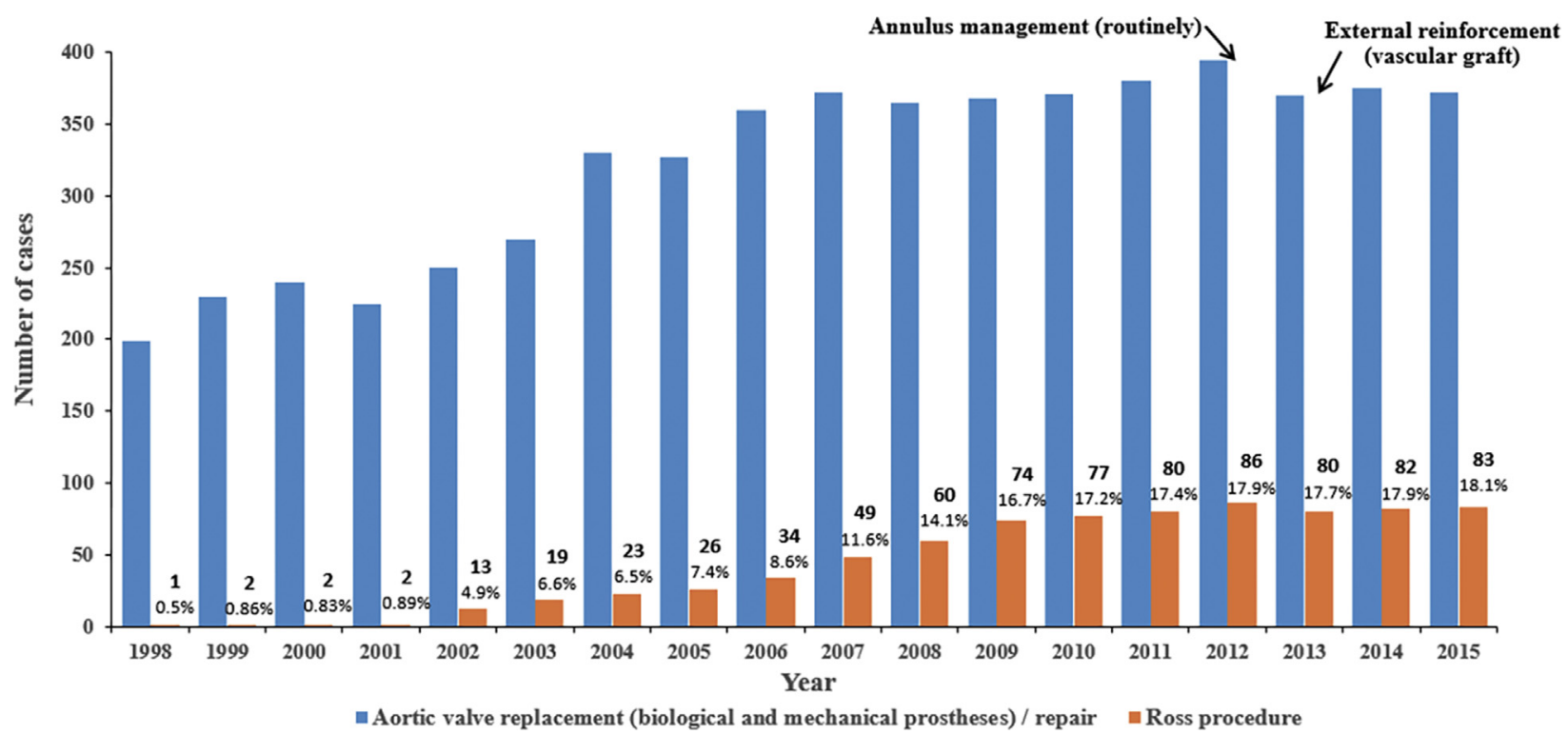

FIGURE E1. Distribution of aortic valve surgeries over the years. The annual absolute number of the Ross procedures and percent of all aortic valve procedures are shown. Arrows represent the time points when technical modifications of the Ross procedure occurred.

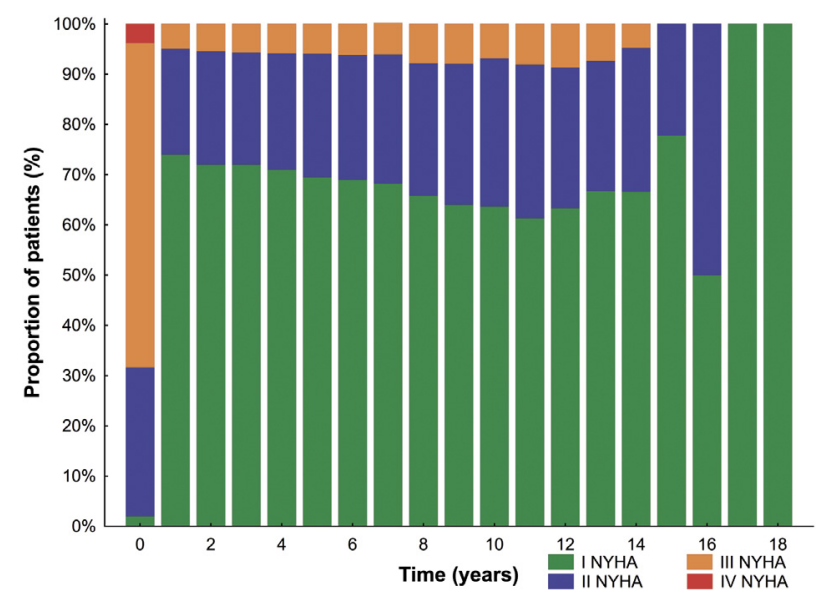

FIGURE E2. New York Heart Association (NYHA) class over time. 

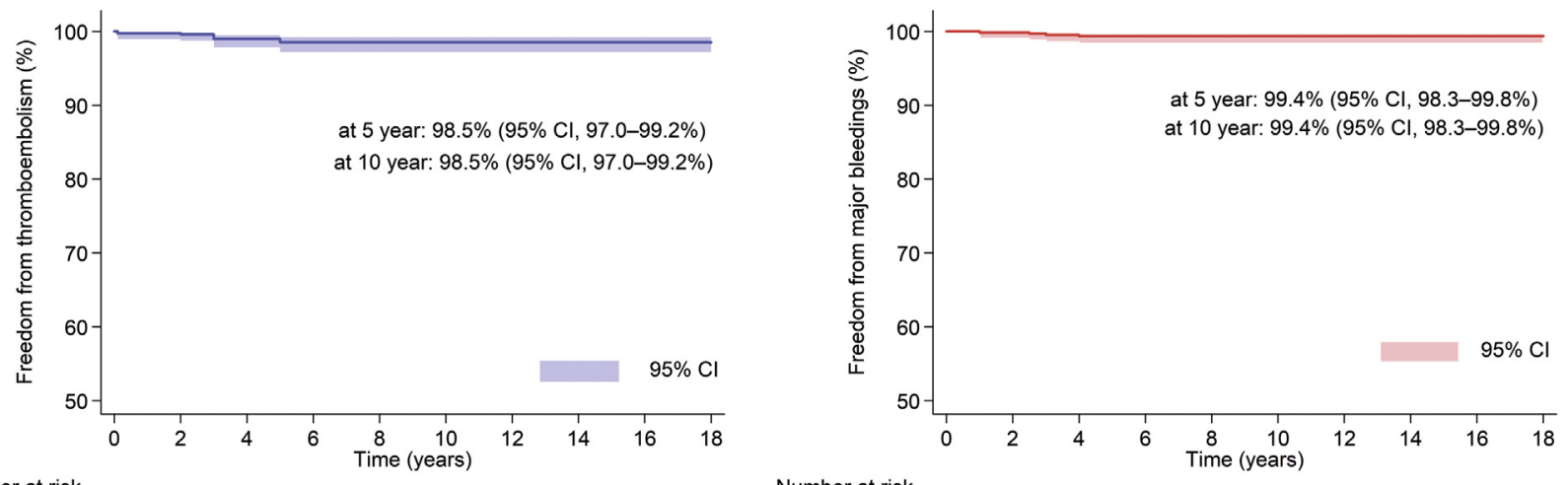

$\begin{array}{llllllllllll}\text { A } & \text { Number at risk } & 793 & 686 & 582 & 377 & 195 & 88 & 46 & 21 & 2 & 1\end{array}$
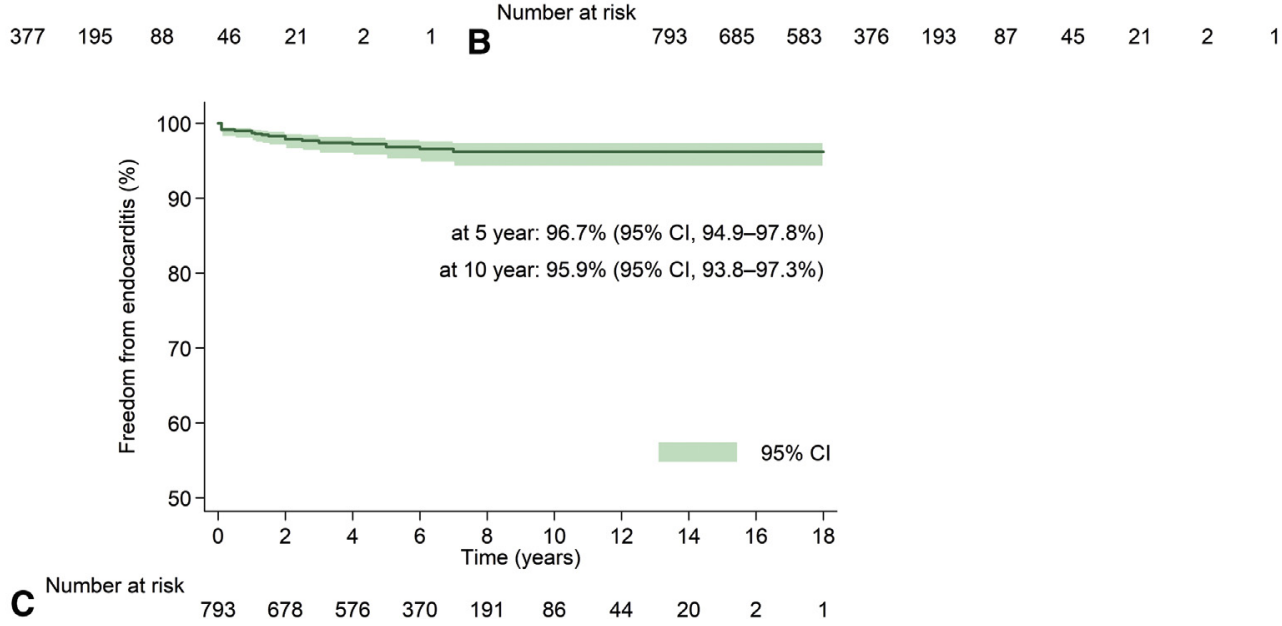

FIGURE E3. Kaplan-Meier curves for freedom from thromboembolism, bleeding, and endocarditis. A, Freedom from thromboembolism. B, Freedom from major bleeding. C, Freedom from endocarditis. CI, Confidence interval.

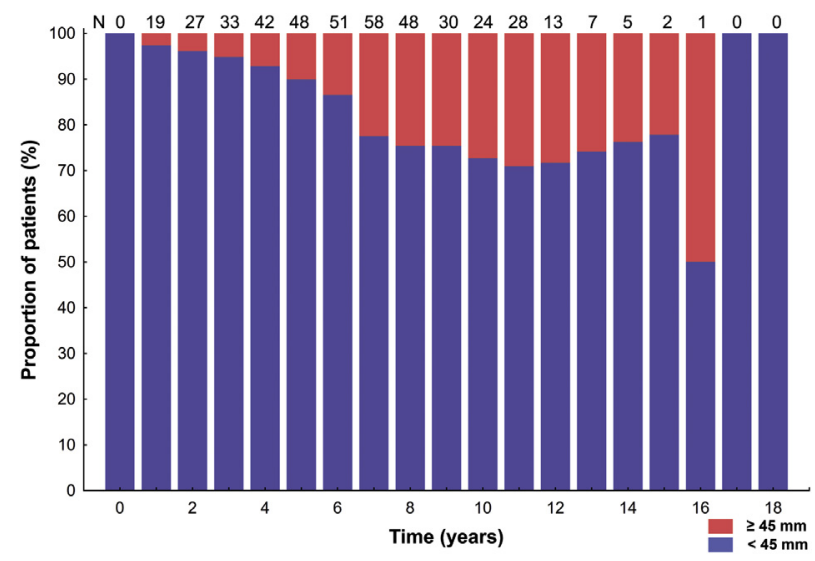

FIGURE E4. Proportion of patients with autograft dilatation ( $\geq 45 \mathrm{~mm})$, over time. $N$, Number of patients with autograft dilatation. 
TABLE E1. Progression of AI over time

\begin{tabular}{lccc}
\hline \multicolumn{1}{c}{ Parameter } & 1 Year & 5 Years & 10 Years \\
\hline Number at risk & 729 & 477 & 88 \\
Reoperation $(95 \%$ CI), \% & $2.1(1.2-3.4)$ & $6.1(4.3-8.6)$ & $11.4(6.1-20.1)$ \\
Degree of AI $(95 \%$ CI), \% & & & \\
No/trace AI & $63.6(60.1-67.1)$ & $49.5(44.9-53.9)$ & $38.6(28.9-49.4)$ \\
Mild AI & $30.6(27.3-34.0)$ & $39.8(35.5-44.3)$ & $46.6(36.3-57.2)$ \\
Moderate AI & $1.4(0.7-2.5)$ & $3.6(2.2-5.7)$ & $3.4(1.1-10.3)$ \\
Severe AI & $0.96(0.46-2.0)$ & $1.0(0.4-2.5)$ & 0 \\
\hline
\end{tabular}

$C I$, Confidence interval; $A I$, aortic insufficiency. 